\title{
A grande dama do feminismo no Brasil
}

Carmen da Silva: o feminismo na imprensa brasileira.

DUARTE, Ana Rita Fonteles.

Fortaleza: Expressã o Gráfica e Editora, 2005. 185 p.

Série História e Memória do J oma lismo.

Muito tem sido escrito sobre a imprensa e as publicações feministas e suas contribuições pa ra a divulgação e orga niza ção do movimento feminista no Brasil. Apesar de Claudia não seruma revista de caráter feminista, a seção A Arte de Ser Mulher (1963 a 1985) e a vida de sua autora, Carmen da Silva, ganharam uma leitora atenciosa e comprometida nos últimos a nos no que tange a essa questão. Ana Rita Fonteles Duarte a presenta neste traba lho uma consistente reflexão sobre a memória de Carmen da Silva e seus escritos na revista Claudia, como um exemplo de pioneirismo nacional no que diz respeito à public ação feminista. Embora a revista Claudia fosse nessa época uma revista em que as representações sobre o gênero feminino permaneciam calcadas num ideário tradicional, revestido por uma tônica modernizante condizente aos anseios da época, Camen da Silva tomou-se precursora nas disc ussões sobre a 
questão da mulher ao desenvolver um trabalho de crítica e divulgação do movimento feminista brasileiro e suas principa is bandeiras de luta.

Carmen da Silva: o feminismo na imprensa brasileira é produto da dissertação de mestrado defendida em 2002 por Ana Rita Fonteles Duarte no Programa de Pós-Graduação em História na Universidade Federal do Ceará. Formada em jornalismo e mestre em História, Ana Rita atualmente é doutoranda em História na Universidade Federal de Santa Catarina. Aliando uma escrita fluente aos debates com a historiog rafia, a autora a presenta um belo estudo sobre Carmen da Silva, comparando suas memórias, lembranças e escritos, no intuito de analisar a vida e a obra da autora como que intrínsecas à construção de seu pensamento e a o contexto com o qual esta dia logava. Partindo de reflexões teónicase metodológicas promovidas pelos estudos de gênero, Ana Rita a presenta um trabalho, em certa medida, biográfic 0 .

o livro divide-se em três capítulos, que tra tam, respec tivamente: da forma ção da revista Claudia e da construção da figura da mulher no Brasil durante dos anos 1960 e 1970; da história de Carmen da Silva e sua formação enquanto feminista; e das fases da "personagem-autora" na seção A Arte de Ser Mulher.

No primeiro capítulo, "Revista com nome de mulher: o feminino no Brasil dosanos 1960-1970", Ana Rita discorre sobre o contexto nacional no qual a revista Claudia foi criada em 1961, pelo Grupo Abril. O Brasil vivia em épocas de cresc ente expansão do capitalismo, submetendo todas as atividades - inclusive a imprensa - à lógica da modemiza ção do país. As mulheres, vista s como as principa is consumidoras dos novos produtos industria liza dos numa sociedade em processo de modemização, tomaram-se o alvo na atenção dos public itá rios. Ana Rita nos mostra como, nesse sentido, Claudia ina ugurou um novo estilo dentre as revistas femininas da época, investindo alto nas reportagens sobre moda e o mundo doméstic 0 . Influenciada pelo american way of life, a "revista amiga" brasileira reafirmava os papéis tradiciona is destina dos às mulheres, contudo, quando as mudanças refletidas pela maior participação da mulher no mercado de trabalho e na educação já não podiam serma is ignoradas, Claudia percebeu que precisaria dar conta dasnovas discussões de maneira diferente do que a té então era feito por outras revistas. É nesse momento que Carmen da Silva fo convidada a entrar para a revista em 1963, ou seja, a revista inaugurou um novo formato ao colocar uma mulher falando para as mulheres, a o contrá rio do que era realizado a té então, quando a presença de mulheresna imprensa era quase nula.

Ana Rita nos mostra ainda que a partir desse momento a revista começou a acompanhar as inquietações das leitoras, mesmo que de maneira bastante limitada, não porque estivesse à frente de seu tempo, mas porque havia possibilidades históric as para que esse diálogo fosse feito. Dessa forma, os ecos dos movimentos feministas penetraram no editorial da revista, e pequenos avanços foram feitos na medida em que as discussões entravam em cena, a tra vés dascartas das leitoras, por exemplo. A própria Carmen da Silva utilizava-se das crític as que recebia a través dessas cartas como um termômetro para o que deveria ser discutido em sua coluna e de que forma.

Abordando a contradição que permeou a história da revista e a seção de Carmen da Silva, Ana Rita afirma que a revista, embora se denominasse como feminina, voltada à mulher esposa-mãe-dona de casa, não poderia deixar de desfraldar algumas das bandeiras feministas da época, como acontecia na seção escrita por Camen da Silva. Dessa forma, a "atitude mais liberal" tomada pela revista era reuniressas "vozes dissonantes" dentro de seu editorial, mesclando o ideal tra dicional a os disc ursos modemizantes.

No segundo capítulo, "Entre memória e história, os caminhos de uma feminista", a autora utiliza principa Imente a autobiografia de Camen da Silva, Histórias híbridas de uma senhora de respeito, e entrevistas com feminista s que tiveram conta to com a jomalista. Confrontando a história pessoal e a obra de sua "personagem-autora" com a história social e política do país, Ana Rita mostra os caminhos percorridos por Carmen desde a sua descoberta da condição da mulher a té sua identific ação com o feminismo de forma atuante, seja no movimento organizado de mulheres, seja através de sua tribuna na revista.

Nascida em Rio Grande, RS, Carmen da Silva nunca se identific ou a o perfil correspondente ao comportamento padrão para as moças de sua época. Ao voltarpara o Brasil em 1962 - depois de passar quase vinte anos morando no Uruguai e na Argentina - quis ajudar a modificar o comportamento da mulher de classe média. Escreveu durante vinte e dois a nos consecutivos a seção A Arte de Ser Mulher, na revista Claudia, popula rizando-se, posteriormente, como "a grande dama do feminismo brasileiro". Aos 63 a nos resolveu esc rever sua biografia no intuito de desmistificarsua própria imagem a os olhos de suas leitoras. Queria mostrarque era uma mulhercomo 
tantas outras, bem como oferecer sua vida como exemplo. Segundo Ana Rita, Carmen da Silva proc urou politizar suas memórias, evidenciando as diferenças e conflitos presentes nas relações entre os gêneros.

Um dos pontos fortes desse capítulo é quando Ana Rita, através da própria história de vida narrada por Carmen da Silva em suas memórias, recorda o movimento feminista brasileiro da década de 1920, quando as mulheres brasileiras reivindicavam o direito ao voto, à educação, à igualda de de remuneração em relação aos homens e a políticas de saúde específic as. Outra questão igualmente relevante é quando a autora fala sobre o boom de public ações de autobiografias femininas durante a década de 1970, do qual Ca men ta mbém fez parte. Conseqüência das rápidas transformações ocomidas tanto no plano comporta mental quanto no político durante a década de 1960, a escrita memorialística feita por mulheres, segundo a autora, ganhou ares de recuperação e reconstrução de uma identida de.

Ana Rita aborda ainda outros pontos interessantes na história de Carmen da Silva, como, por exemplo, suas leituras, influências, sua "tomada de consciência" para as questões relativas à diferença de tra ta mento entre homens e mulheres, seu trabalho na revista, etc. Quando terminamos a leitura desse capítulo, deparamonos com uma personagem excepcional a nossa frente. A escrita de Ana Rita nosa presenta Carmen de maneira apaixonante, a ponto de estarmos tota Imente familizarizadas/os com sua história e aptas/os a compreender o pioneirismo de seus escritos para o movimento feminista nacional, tratados no terceiro e último capítulo.

Em "Percorrendo trilhas", Ana Rita aborda as fases do trabalho de Carmen da Silva junto às mulheres através da revista Claudia e do movimento feminista. Nessa parte do trabalho, a autora utiliza principalmente as coletâneas de artigos organizadas por Carmen da Silva. No intuito de reconstruir sua vida a tra vés da memória, Carmen escreveu não só sua própria história como também reavaliou seus trabalhos e os momentos vividos na revista. As duas coletâneas que organizou serviram para fazer um balanço de sua produção, e como uma forma de documentaras mudanças. Ana lisando o processo histórico, Carmen, como nos mostra Ana Rita, dividiu seu trabalho em quatro fases de acordo com as temátic as recorrentes.

Na primeira fase, em 1963, a preoc upação de Carmen consistia em chamara atenção das mulheres para a necessidade de se perceberem enquanto indivíduos, numa tenta tiva de "descoberta de si". Nesse momento, Carmen a presentava um discurso moderado, usando do estilo psicanalític o para orientar suas leitoras. A segunda fase de seu trabalho, segunda metade da década de 1960, Carmen considera uma etapa de "descoisific ação" e "desa lienação" das mulheres. Diante da frustração das mulheres com o casamento, a jomalista debateu temas como a infidelidade, o divórcio e o adultério, sem, no entanto, vitimizar as mulheres. Na terceira fase de seu trabalho (1971), encontramos uma Carmen mais explicitamente engajada com a causa feminista, começando a discutir a partir de uma perspectiva de crítica polític a a sexismo e à dominação masculina, na tentativa de desnatura lizar as diferenças de gênero. A última fase, iniciada em 1979, é marcada pela a utocrític a em relação a a lguns dos pressupostos do movimento feminista internacional e pela ligação da jornalista a o movimento de valorização da diferença. Nesse momento, Ca men substitui o disc urso da luta de classespela defesa de uma cultura feminina.

0 interessante a ressalta rmos nesse ca pítulo é a construção de Carmen da Silva enquanto feminista e sua atuação através de sua tribuna na revista Claudia. Ana Rita nos apresenta com clareza o quanto a seção A Arte de Ser Mulher representou para uma vitória na batalha pelo poder do discurso em favor do movimento feminista. Em alguns momentos as idéias da jomalista chocaram-se com o editorial da revista, fazendo-se necessárias a negociação e a utilização de estratégias para que seu discurso nesse espaço fosse preservado.

Em uma avaliação final, Ana Rita atenta para o pioneirismo de Carmen da Silva e sua contribuição para o movimento feminista no Brasil. Através de pequenas aberturas que a revista Claudia possibilitava em favor de um discurso modernizante, Carmen conseguiu criar não a penas um lugardiferenciado, mas ta mbém um espaço de debate e mudança.

O trabalho de Ana Rita é um exemplo brilhante dentre as produções que nos últimos tempos têm se preocupado em contribuir para a compreensão da história dos feminismos no Brasil e da vivência de suas personagens, partindo de uma perspectiva historiográfica que situa as mulheres.

Joana Vieira Borges

Universidade Federal de Santa Catarina 